\title{
Evidence for a Novel Phylotype of Pseudomonas syringae Causing Bacterial Leaf Blight of Cantaloupe in China
}

Yanli Tian, College of Plant Protection and Key Laboratory of Integrated Management of Crop Diseases and Pests, Ministry of Education, Nanjing Agricultural University, Nanjing 210095, China; Yuqiang Zhao, Institute of Botany, Jiangsu Province and the Chinese Academy of Sciences, Nanjing 210014, China; Xuezi Chen and Yuanfeng Dai, College of Plant Protection and Key Laboratory of Integrated Management of Crop Diseases and Pests, Ministry of Education, Nanjing Agricultural University, Nanjing 210095, China; Wenjun Zhao, Chinese Academy of Inspection and Quarantine, Beijing, 100029, China; Baishi Hu, ${ }^{\dagger}$ College of Plant Protection and Key Laboratory of Integrated Management of Crop Diseases and Pests, Ministry of Education, Nanjing Agricultural University, Nanjing 210095, China and National Engineering Research Center for Cucurbits, Changji 831100, China; and R. R. Walcott, ${ }^{\dagger}$ Department of Plant Pathology, The University of Georgia, Athens 30602

\begin{abstract}
Bacterial leaf blight (BLB) has caused severe yield losses in cantaloupe (Cucumis melo L.) in the major melon-growing regions of China since the beginning of the twentieth century. Historically, Pseudomonas syringae pv. lachrymans was considered to be the causal agent of BLB of cantaloupe and angular leaf spot of cucumber. In the process of characterizing bacteria isolated from cantaloupe, we observed that putative $P$. syringae pv. lachrymans yielded negative results in $P$. syringae pv. lachrymans-specific PCR assays. This suggested that the $P$. syringae pv. lachrymans-like strains from cantaloupe were distinct from those recovered from cucumber. To investigate the differences between $P$. syringae pv. lachrymans-like strains isolated from cantaloupe and cucumber, 13 P. syringae strains isolated from cantaloupe [12 from China and 1 from Zimbabwe (NCPPB2916)] and 7 additional $P$. syringae reference strains were analyzed by catabolic profiling, phylogenetic analysis

by multilocus sequence analysis (MLSA) and pathogenicity tests on cantaloupe leaflets. Catabolic profiling and MLSA based on 10 housekeeping genes and 2 hypersensitive response and pathogenicity ( $h r p$ ) genes allowed us to differentiate strains isolated from cantaloupe and cucumber. Pseudomonas syringae pv. lachrymans strains isolated from cucumber clustered with genomospecies 2 , and $13 P$. syringae strains isolated from cantaloupe belonged to genomospecies 1 . While all cantaloupe strains were closely related to $P$. syringae pv. aptata, they could be differentiated from this pathovar based on metabolic tests and MLSA. Pathogenicity tests showed that all strains isolated from cantaloupe and cucumber were only pathogenic on their original hosts. Based on these observations we conclude that $P$. syringae pv. lachrymans strains recovered from cantaloupe in China represent a novel phylotype.
\end{abstract}

Cantaloupe (Cucumis melo L.) is an economically important crop in northern China, which produces approximately 10,000,000 tons of fruit annually on about 400,000 ha of land (Wang et al. 2014). Of the many melon types planted in China, the "Hami Melon" (C. melo subsp. melo var. cantalupo) is the dominant type planted in northern China. Since the beginning of twentieth century, bacterial leaf blight (BLB) has been reported in all major melon-growing regions of China, and the causal agent has been identified as Pseudomonas syringae pv. lachrymans (Wei 2009; Zhang et al. 2002). BLB symptoms include water-soaked, irregular spots with yellow halos. These lesions eventually turn brown and necrotic over time. Symptoms of BLB on cantaloupe foliage are similar to those caused by Acidovorax citrulli, the causal agent of bacterial fruit blotch (Schaad et al. 1978, 2008; Willems et al. 1992). However, symptoms are generally inconspicuous on fruits compared with the typical water-soaked blotches caused by A. citrulli. With severe BLB epidemics, 30 to $100 \%$ cantaloupe yield loss has been reported (Zeng et al. 2013; Zhang et al. 2002).

The species Pseudomonas syringae includes gram-negative bacteria that cause diseases on a wide range of plant species. The term "pathovar" refers to $P$. syringae strains that are differentiated at the subspecies level based on differences in plant host range, types of

${ }^{\dagger}$ Corresponding authors. B. Hu, hbs@njau.edu.cn; and R. R. Walcott, rwalcott@uga.edu

The first two authors contributed equally to this research.

*The $\boldsymbol{e}$-Xtra logo stands for "electronic extra" and indicates that one supplementary table is published online.

Accepted for publication 21 June 2017.

() 2017 The American Phytopathological Society symptoms induced, and biochemical profiles (Dye et al. 1980; Schaad et al. 2001). Recently, phylogenetic analysis of housekeeping gene (HKG) sequences was used to infer relatedness between $P$. syringae strains. This approach demonstrated higher resolution than other commonly employed methods (Ait Tayeb et al. 2005; Parkinson et al. 2010; Sarkar et al. 2006). Multilocus sequence typing (MLST) accurately segregated $P$. syringae strains into their corresponding genomospecies and revealed new levels of genetic diversity (Bull et al. 2011). Gutiérrez-Barranquero et al. (2013) reported that MLST strongly supports the existence of a phylotype of $P$. syringae pv. syringae that is mainly associated with mango (Mangifera indica L.). Inoue and Takikawa (2006) also reported that the sequences of the pathogenicity-related genes, $h r p Z$ and $h r p A$, are useful for phylogenetic analysis of $P$. syringae pathovars.

Some $P$. syringae strains that are not members of the pathovar lachrymans have been reported to cause disease on cantaloupe. However, the pathovar designation for these strains is debatable and has not been verified. For example, Blancard et al. (1991) reported that $P$. syringae occasionally caused disease outbreaks on cantaloupe under greenhouse conditions in Spain. However, none of these strains are currently available to allow confirmation of their pathovar status. Additionally, Smith (1946) reported sunken spots on honeydew fruits caused by $P$. syringae pv. lachrymans, while a strain isolated from $C$. melo in New Zealand was identified as $P$. syringae pv. syringae (Young 1991). Unfortunately, the pathogenicity and host range of these strains was not comprehensively assessed.

In 2000, Morris et al. (2000) attributed a cantaloupe blight outbreak that occurred in France to $P$. syringae pv. aptata based on biochemical tests, plasmid and chromosome profiling, and host range studies. Most recently, Newberry et al. (2016) demonstrated that $P$. syringae populations associated with angular leaf spot of watermelon, cantaloupe, and squash in the United States were genetically distinct from $P$. syringae pv. lachrymans.

In China, $P$. syringae pv. lachrymans has generally been considered the causal agent of BLB of melon (Sun and He 1988; Wang 
et al. 2012; Ye and Ding 2001). Unfortunately, however, most reports do not comprehensively characterize the strains, or only rely on simple physiological tests or $16 \mathrm{~S}$ rRNA gene sequence analysis. While 16S rRNA gene sequence analysis is widely employed in bacterial classification, most $P$. syringae pathovars cannot be differentiated based on this gene.

While characterizing bacteria isolated from symptomatic cantaloupe in China, we observed that all presumptive $P$. syringae pv. lachrymans strains yielded negative results with $P$. syringae pv. lachrymansspecific PCR assays (Wang et al. 2011). This suggested that $P$. syringae pv. lachrymans strains associated with infected cantaloupe were genetically different from those isolated from cucumber. The objective of this work was to characterize a population of $P$. syringae strains infecting cantaloupe in China.

\section{Materials and Methods}

Bacterial strains and growth conditions. Cantaloupe leaves with BLB symptoms were surface sterilized with $75 \%$ ethanol and allowed to air dry. Small pieces of tissue from the margins of lesions were ground in sterilized water, and then left at room temperature for $5 \mathrm{~min}$. Aliquots of the macerated leaf tissue were streaked onto LuriaBertani (LB) medium, incubated at $28^{\circ} \mathrm{C}$ for $24 \mathrm{~h}$, and then subcultured onto $\mathrm{LB}$ medium to obtain single colonies. Pure isolates of the bacteria from leaves with BLB symptoms were tested for induction of a hypersensitive response by infiltrating fully developed leaves of Nicotiana tabacum cv. Samsun plants with bacterial suspensions [approximately $1 \times 10^{8}$ colony-forming units $(\mathrm{cfu}) / \mathrm{ml}$ ] of 16-h-old cultures. Bacterial strains that induced the hypersensitive response in plants within $16 \mathrm{~h}$ of incubation at $28^{\circ} \mathrm{C}$ were further characterized for pathogenicity on their original hosts by sprayinoculation assays $\left(1 \times 10^{6} \mathrm{cfu} / \mathrm{ml}\right)$. For inoculation, plants were spray-inoculated with the bacterial suspensions until run-off. For each strain, five plants of each variety were inoculated. Plants spray-inoculated in a similar manner with sterilized distilled water served as negative controls. After inoculation, plants were incubated in plastic pots containing soil in the conditioned chambers of the

Table 1. Pseudomonas syringae strains used in this study

\begin{tabular}{|c|c|c|c|c|c|c|}
\hline \multicolumn{2}{|c|}{$\begin{array}{l}\text { Pseudomonas syringae pathovar } \\
\text { and strain }\end{array}$} & \multirow{2}{*}{$\begin{array}{c}\text { Geographical origin } \\
\text { Xinjiang (China) }\end{array}$} & Host & Year & \multirow{2}{*}{ Genomospecies $^{\mathbf{a}}$} & \multirow{2}{*}{$\frac{\text { Source }^{\mathbf{b}}}{\text { NJAU }}$} \\
\hline & NJL16 & & Cиситis melo & 2006 & & \\
\hline & NJL18 & Xinjiang (China) & Cucumis melo & 2006 & 1 & NJAU \\
\hline & 361 & Xinjiang (China) & Cucumis melo & 2011 & 1 & NJAU \\
\hline & 362 & Xinjiang (China) & Cucumis melo & 2012 & 1 & NJAU \\
\hline & 371 & Xinjiang (China) & Cucumis melo & 2012 & 1 & NJAU \\
\hline & 384 & Xinjiang (China) & Cuситis melo & 2013 & 1 & NJAU \\
\hline & 501 & Xinjiang (China) & Cucumis melo & 2013 & 1 & NJAU \\
\hline & 404 & Inner Mongolia (China) & Cucumis melo & 2011 & 1 & NJAU \\
\hline & 451 & Inner Mongolia (China) & Cucumis melo & 2012 & 1 & NJAU \\
\hline & 492 & Inner Mongolia (China) & Cucumis melo & 2012 & 1 & NJAU \\
\hline & 503 & Gansu (China) & Cucumis melo & 2011 & 1 & NJAU \\
\hline & 504 & Gansu (China) & Cucumis melo & 2012 & 1 & NJAU \\
\hline & NCPPB2916 & Zimbabwe & Cucumis melo & 1977 & 1 & CAIQ \\
\hline \multirow[t]{4}{*}{ lachrymans } & NCPPB1096 & Hungary & Cucumis sativus & 1961 & 2 & CAIQ \\
\hline & NCPPB277 & Denmark & Cucumis sativus & 1950 & 2 & CAIQ \\
\hline & JL-1 & Jilin (China) & Cucumis sativus & 2012 & 2 & NJAU \\
\hline & JL-2 & Jilin (China) & Cucumis sativus & 2012 & 2 & NJAU \\
\hline \multirow[t]{2}{*}{ aptata } & NCPPB3539 & UK & Beta vulgaris & 1987 & 1 & UGA \\
\hline & $17-1$ & USA & Beta vulgaris & Unknown & 1 & UGA \\
\hline syringae & NCPPB 1770 & UK & Phaseolus vulgaris & 1965 & 1 & UGA \\
\hline
\end{tabular}

${ }^{a}$ Genomospecies according to Gardan et al. (1999).

${ }^{\mathrm{b}}$ NJAU = Nanjing Agricultural University; CAIQ = Chinese Academy of Inspection and Quarantine; UGA = University of Georgia.

${ }^{c}$ NCPPB2916 = a melon strain that was recorded as $P$. syringae pv. lachrymans (http://ncppb.fera.defra.gov.uk/ncppbresult.cfm).

Table 2. Oligonucleotide primers used for multilocus sequence analysis of Pseudomonas syringae strains in this study

\begin{tabular}{llcc}
\hline Primer & \multicolumn{1}{c}{ Sequence $\left(\mathbf{5}^{\prime} \mathbf{-} \mathbf{3}^{\prime}\right)$} & $\begin{array}{c}\text { Annealing } \\
\text { temperature }\left({ }^{\circ} \mathbf{C}\right)\end{array}$ & Reference \\
\hline gapA(ps) & CGCCATYCGCAACCCG/CCCAYTCGTTGTCGTACCA & 62 & Sarkar and Guttman 2004 \\
gltA(p) & GCCTCBTGCGAGTCGAAGATCACC/CTTGTAVGGRCYGGAGAGCATTTC & 62 & Hwang et al. 2005 \\
gltA(s) & CCTGRTCGCCAAGATGCCGAC/CGAAGATCACGGTGAACATGCTGG & 62 & Hwang et al. 2005 \\
gyrB(ps) & MGGCGGYAAGTTCGATGACAAYTC/TRATBKCAGTCARACCTTCRCGSGC & 63 & Sarkar and Guttman 2004 \\
rpoB(ps) & TGGCCGGTCGTCACGGTAACA/CCGAAACGCTGACCACCGAAC & 62 & Andreani et al. 2014 \\
rpoD(p) & AAGGCGARATCGAAATCGCCAAGCG/GGAACWKGCGCAGGAAGTCGGCACG & 63 & Sarkar and Guttman 2004 \\
rpoD(s) & AAGCGAATCGAAGAAGGCATYCGTG/GGAACWKGCGCAGGAAGTCGGCACG & 63 & Sarkar and Guttman 2004 \\
glnS(ps) & ACCAACCCGGCCAAGAAGACCAGG/TGCTTGAGCTTGCGCTTG & 62 & Andreani et al. 2014 \\
ileS(ps) & TTCCCAATGAARGCCGGCCTGCC/GGGGTGGTGGTCCAGATCACG & 62 & Andreani et al. 2014 \\
pgi(p) & TGCAGGACTTCAGCATGCGCGAAGC/CGAGCCGCCCTGSGCCAGGTACCAG & 60 & James et al. 2014 \\
pgi(s) & TTCAGCATGCGCGAAGCG/ TGCGCCAAGGTACCAGG & 60 & James et al. 2014 \\
acn(p) & ACATCCCGCTGCACGCYCTGGCC/GTGGTGTCCTGGGAACCGACGGTG & 60 & Sarkar and Guttman 2004 \\
acn(s) & ATGAARCAGATMGAAGAAATGCGCGG/GCCRACCATCTTYTGCGCMAGGG & 60 & Sarkar and Guttman 2004 \\
pfk(p) & ACCMTGAACCCKGCGCTGGA/ATRCCGAAVCCGAHCTGGGT & 63 & James et al. 2014 \\
pfk(s) & AGCAAYATCAAGMTGGCCGA/ ACCATGCCKGCCARMAGCG & 63 & James et al. 2014 \\
HrpZ,A(ps) & ACGATCAASCTGGATRTCTG/TGNAGRTTNGTNAGYTTRTC & 60 & Inoue and Takikawa 2006 \\
\hline & & &
\end{tabular}


Climacell 222 (Medcenter Gmbh, Planegg, Germany) at 100\% relative humidity (RH) and $28^{\circ} \mathrm{C}$ for 14 days with $12 \mathrm{~h}$ natural sunlight daily. Bacterial strains that were pathogenic to their original hosts were preserved.

Thirteen $P$. syringae pv. lachrymans strains were used in this study (Table 1). Among them, 12 strains were isolated from cantaloupe from different regions in China; and one strain, NCPPB2916, was isolated from melon in Zimbabwe in 1977 (http://ncppb.fera.defra. gov.uk/furtherinfo.cfm?ncppb_no=2916). Additionally, we analyzed four $P$. syringae $\mathrm{pv}$. lachrymans strains isolated from cucumber, two $P$. syringae pv. aptata strains, and one $P$. syringae pv. syringae strain. For virulence tests, three strains (NJL18, 503, and 451) isolated from cantaloupe, two strains (NCPPB1096 and JL-1) isolated from cucumber, one strain (NCPPB3539) isolated from beet, and $P$. syringae pv. syringae (NCPPB1770) were compared. All strains were routinely cultured in LB media at $28^{\circ} \mathrm{C}$ for $24 \mathrm{~h}$.

DNA extraction, PCR amplification, and sequencing. Genomic DNA was extracted from $2 \mathrm{ml}$ of overnight culture of each $P$. syringae strain cultured in LB broth using the TIANamp Bacteria DNA Kit (TIANamp BIOTECH, Beijing, China) according to the manufacturer's directions. In addition to the $16 \mathrm{~S}$ rRNA gene, $10 \mathrm{HKGs}$ [gapA (glyceraldehyde-3-phosphate dehydrogenase), gltA (glutamate synthase), $g y r B$ (DNA gyrase beta subunit), $r p o B$ (RNA polymerasebeta subunit), $r p o D$ (RNA polymerasesigma 70 subunit), $g \ln S$ (glutaminyltRNA synthetase), ileS (isoleucyl- tRNA synthetase), pgi (glucose-6phosphate isomerase), acn (aconitase), pfk (phosphofructokinase)] and $2 h r p$ genes $(h r p Z$ and $h r p A)$ were amplified by PCR assay using appropriate olignucleotide primers (Table 2 ).

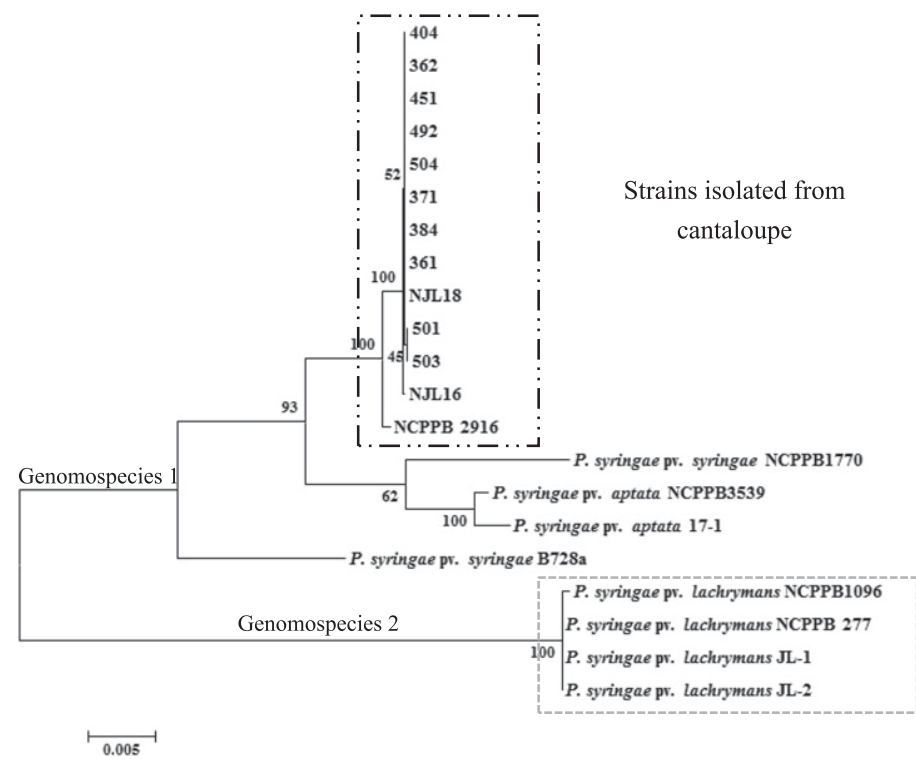

Strains isolated

from cucumber

Fig. 1. Phylogeny of Pseudomonas syringae strains based on multilocus sequence analysis of 10 housekeeping genes. The neighbor-joining tree was constructed with combined partial sequences of gapA, gltA, gyrB, rpoB, rpoD, glnS, ileS, pgi, acn, and pfk genes using MEGA 5.10. The maximum-likelihood method and the nearest-neighbor-interchange were used to improve the likelihood of the tree. Bootstrap percentages were calculated based 1,000 replicates.

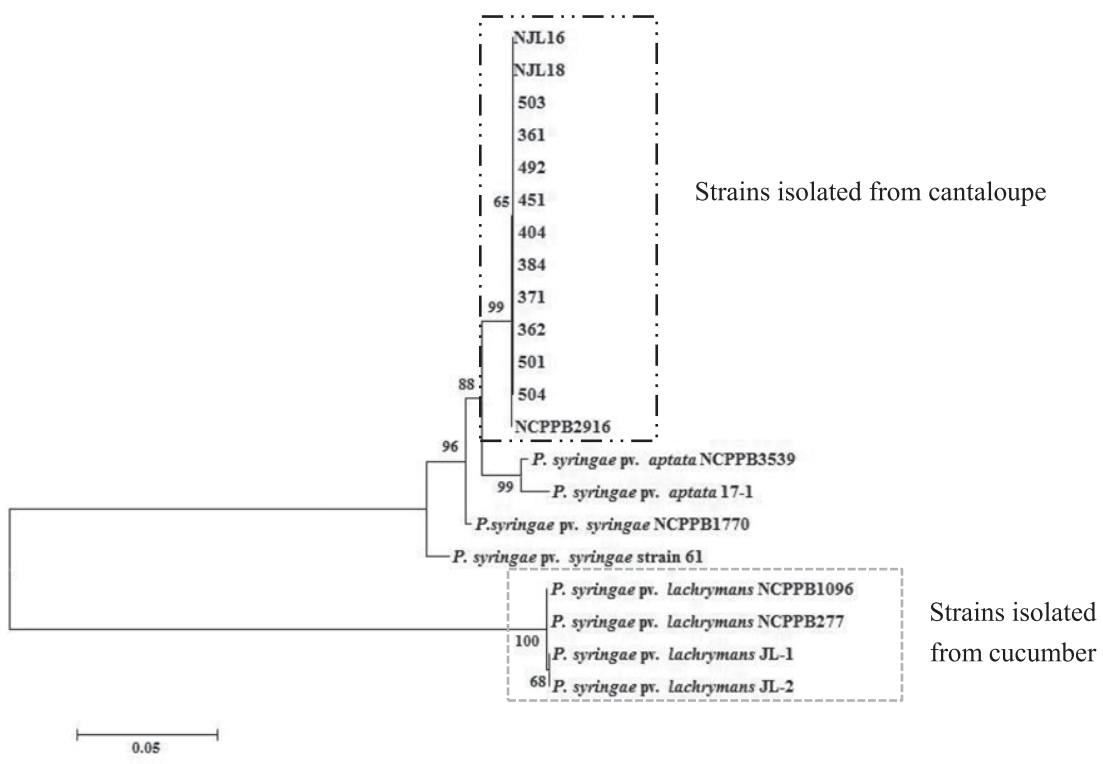

Fig. 2. Phylogeny of Pseudomonas syringae strains based on multilocus sequence analysis of concatenated partial sequences on the hypersensitive response and pathogenicity (hrp) genes, hrpZ and hrpA. The neighbor-joining tree was constructed using MEGA 5.10. The ML method and the nearest-neighbor-interchange were used to improve the likelihood of the tree. Bootstrap percentages were calculated based on 1,000 replicates. 
Each $50 \mu \mathrm{l}$ amplification reaction contained $1 \mu \mathrm{l}$ of template DNA $(5 \mathrm{ng}), 5 \mu \mathrm{l}$ of $10 \times$ PCR buffer, $1 \mu \mathrm{l}$ each of PCR primer $(10 \mathrm{mM})$, $1 \mu \mathrm{l}$ of dNTP mix $(10 \mathrm{mM}), 6 \mu \mathrm{l}$ of $\mathrm{MgCl}_{2}(25 \mathrm{mM}), 2.5 \mathrm{U}$ of Taq DNA polymerase (TaKaRa, Dalian, China), and $34 \mu \mathrm{l}$ of sterilized water. PCR was performed using an 2720 thermal cycler (Applied Biosystems, Singapore) with the following thermal profile: $5 \mathrm{~min}$ at $95^{\circ} \mathrm{C}$ for initial denaturation, followed by 30 cycles of denaturation at $95^{\circ} \mathrm{C}$ for $30 \mathrm{~s}$, annealing for $30 \mathrm{~s}$ at the primer-pair-specific annealing temperature (Table 2), and extension at $72^{\circ} \mathrm{C}$ for $30 \mathrm{~s}$. A final extension was performed at $72^{\circ} \mathrm{C}$ for $10 \mathrm{~min}$. Following this initial PCR reaction, the amplicons were purified using AxyPrep PCR cleanup reagent (Axygen, Hangzhou, China) in accordance with the manufacturer's instructions. The amplicons were used for direct Sanger sequencing (Lifetechnologies, Nanjing, China) with the appropriate sequencing primers (Table 2).

Multilocus sequence analysis. The accession numbers of the sequences used in this study are included in Supplemental Table 1. Phylogenetic trees were generated using MEGA 5.10 (Tamura et al. 2011) with neighbor-joining. Confidence levels of the branch points were determined using 1,000 bootstrap replicates.

Catabolic profiling. The catabolic activity of the representative P. syringae strains (Table 1) on 71 carbon sources plus 23 chemical sensitivity assays were tested using a Biolog GENIII MicroPlate (BIOLOG, CA, USA) analysis according to the manufacturer's protocol. Briefly, bacterial strains were grown on BUG+B plates (BIOLOG) for $24 \mathrm{~h}$ and then cells were suspended in inoculating Fluid A (BIOLOG). Cell suspensions were adjusted to approximately 95\% transmission using a turbidometer (BIOLOG), and aliquots $(150 \mu \mathrm{l})$ were loaded into GenIII plates. Plates were incubated for

Table 3. Biochemical characteristics of Pseudomonas syringae strains as determined by BIOLOG GENIII MicroPlate

\begin{tabular}{llll}
\hline Characteristic & $\mathbf{1}^{\mathrm{a}}$ & $\mathbf{2}$ & $\mathbf{3}$ \\
\hline D-fructose & $+\mathrm{b}$ & - & + \\
Bromo-succinic acid & + & - & - \\
Pectin & - & + & - \\
L-alanine & - & + & + \\
L-glutamic acid & - & - & + \\
Citric acid & - & + & + \\
D-galactose & + & - & + \\
\hline
\end{tabular}

${ }^{\text {a }}$ Species (strain numbers for this study and references to previous studies are indicated where applicable): $1=13 P$. syringae strains isolated from cantaloupe listed in Table 1;2 = P. syringae pv. lachrymans strains NCPPB1096, NCPPB277, JL-1; and JL-2; $3=P$. syringae pv. aptata strains NCPPB3539 and $17-1$.

$\mathrm{b}_{+}$, positive; - , negative. up to $24 \mathrm{~h}$ at $28^{\circ} \mathrm{C}$ in the Omnilog system (BIOLOG) and data were collected at the end of the 24-h period. A binary matrix was constructed for cluster analysis by assigning a value for each substrate as follows: 0 for negative result (no catabolism) and 1 for positive result (catabolism). Two independent plates were used per strain. Jaccard's similarity coefficient was generated for the binary data using the SPSS statistical analysis Version 19.0 (Sneath and Sokal 1973).

Virulence tests. To determine the virulence of the $P$. syringae strains, 3-week-old seedlings (3rd leaf stage) of three melon varieties (Cucumis melo subsp. melo var. cantalupo cv. Huanghou; C. melo subsp. melo var. chinensis cv. Tianbao; and, C. melo subsp. melo var. cassaba cv. Huanghemi) and three cucumber varieties (C. sativus cv. Jinchun-2, Jinyan-1, and Jufeng-8) were used because they represent the major cultivated varieties in China. Cells from an overnight LB agar plate culture of each $P$. syringae strain were suspended in sterilized water, adjusted with a spectrophotometer (Eppendorf, Hamburg, Germany) to an optical density of 0.3 at a wavelength of $600 \mathrm{~nm}$, and then diluted 100-fold $\left(\sim 1 \times 10^{6} \mathrm{cfu} / \mathrm{ml}\right)$. For inoculation, plants were spray-inoculated with the bacterial suspensions until run-off. For each strain, five plants of each variety were inoculated. Plants sprayinoculated in a similar manner with sterilized distilled water served as negative controls. After inoculation, plants were incubated in plastic pots containing soil in the conditioned chambers of the Climacell 222 at $100 \% \mathrm{RH}$ and $28^{\circ} \mathrm{C}$ for 14 days with $12 \mathrm{~h}$ light daily. At 14 days postinoculation (dpi), the disease severity was assessed by calculating the percentage of leaflets area that was necrotic and scored using the following scale: $0 \%$, not pathogenic; $\geq 1$ to $<25 \%$, low virulence; $\geq 25$ to $<50 \%$, intermediate virulence; and $\geq 50 \%$, high virulence. The one-way Student's $t$ test $(P=0.05)$ was used to determine significant differences in disease severity among different strains of $P$. syringae using SPSS 14.0 (SPSS Inc., Chicago, IL, USA). The experiment was repeated three times with similar results.

\section{Results}

$P$. syringae strains clustered based on the host of isolation. A phylogenetic tree was generated based on the concatenated sequences of HKGs with a total length of 5,711 nucleotides in the following order: gapA, gltA, gyrB, rpoB, rpoD, glnS, ileS, pgi, acn, and pfk (Fig. 1). Two main MLSA phylogroups were observed (Fig. 2) in which $P$. syringae strains clustered based on the host of isolation. The MLSA phylogroups were designated as I for strains isolated from cantaloupe and II for strains isolated from cucumber, and $P$. syringae pv. lachrymans strain NCPPB1096, which is a member of Genomospecies 2 . Another phylogenetic tree was generated based on the concatenated sequences of the hrpZ and hrpA genes (Fig. 2). Again, $P$. syringae strains clustered based on the host of isolation, and the tree was in agreement with clusters based on MLSA with the 10 HKGs.

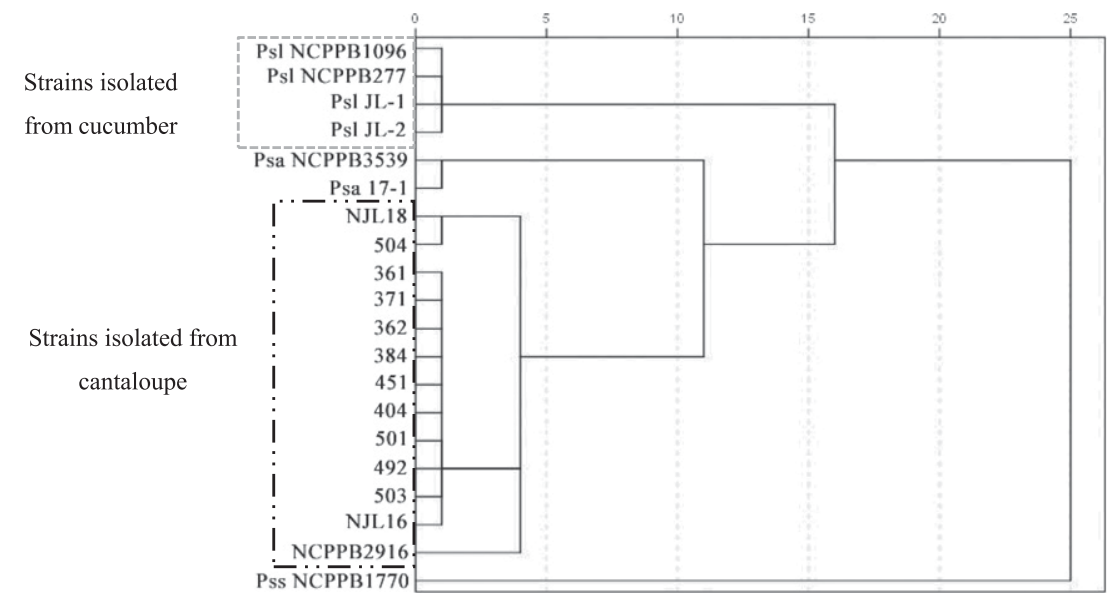

Fig. 3. Cluster analysis of representative Pseudomonas syringae strains based on their catabolysis of 71 carbon sources and sensitivity to 23 chemicals (Biolog GNIII). Jaccard's similarity coefficient was used to generate a dendrogram using the SPSS Statistics 19.0 software (IBM), and unweighted pair-group method with average linkages. 
The $P$. syringae strains did not cluster based on geographical origin regardless of the genes analyzed.

Catabolic profiles of $P$. syringae strains support the phylogenetic analysis based on MLSA. The catabolic profiles of the tested $P$. syringae strains are presented in Table 3. Six reactions, i.e., growth on D-fructose, bromo-succinic acid, pectin, L-alanine, L-glutamic acid, and D-galactose differentiated $13 P$. syringae strains isolated from cantaloupe and $4 P$. syringae pv. lachrymans strains isolated from cucumber. Four reactions, i.e., growth on bromo-succinic acid, L-alanine, L-glutamic acid, and citric acid differentiated 13 P. syringae strains isolated from cantaloupe and $2 P$. syringae pv. aptata strains.

The phenotypic distribution tree of the $P$. syringae strains based on catabolic profiles on 71 carbon sources and 23 chemical sensitivity assays revealed that the $13 P$. syringae strains isolated from cantaloupe clustered apart from $P$. syringae pv. lachrymans strains isolated from cucumber (Fig. 3). Instead, these P. syringae strains clustered with the reference $P$. syringae pv. aptata strains.

Virulence of $P$. syringae strains. Three representative $P$. syringae strains [NJL18 (from Xinjiang province), 503 (from Gansu province), and 451 (from Inner Mongolia province)] isolated from cantaloupe induced intermediate levels of disease severity $(\geq 25$ to $<50 \%)$ on 3-week-old melon ( $C$. melo subsp. melo var. cantalupo cv. Huanghou) seedlings. However, they induced a low degree of severity ( $\geq 1$ to $<25 \%$ ) on two other melon varieties (C. melo subsp. melo var. chinensis cv. Tianbao and C. melo subsp. melo var. cassaba cv. Huanghemi) (Fig. 4). As expected, the negative control melon leaves treated with sterilized water did not develop lesions. The two $P$. syringae pv. lachrymans strains (NCPPB1096 and JL-1), one $P$. syringae pv. aptata strain (NCPPB3539), and one $P$. syringae pv. syringae strain (NCPPB1770) did not induce lesions on melon seedlings (Fig. 4). Differences in disease severity between the $P$. syringae strains isolated from cantaloupe and the other $P$. syringae strains were significant $(P<0.05)$.

In addition, the three $P$. syringae strains (NJL18, 503, and 451) isolated from cantaloupe were not pathogenic on three varieties of cucumber (Fig. 5). Differences in disease severity between the $P$. syringae strains isolated from cantaloupe and $P$. syringae pv. lachrymans strains isolated from cucumber were significant $(P<0.05)$.

\section{Discussion}

Pseudomonas syringae pv. lachrymans has been reported to be pathogenic to members of the Cucurbitaceae family including cucumber, watermelon, cantaloupe, muskmelon, squash, and pumpkin (Bradbury 1986). In the current study, we evaluated the genetic and phenotypic diversity of a population of $P$. syringae strains isolated from cantaloupe and other hosts from China and other geographical regions. We observed that $P$. syringae strains associated with BLB of cantaloupe in China were distinct from $P$. syringae pv. lachrymans strains associated with leaf spot disease of cucumber. Our observations agree with recent reports that $P$. syringae strains that cause blighting on watermelon, cantaloupe, and squash in the United States and France are phylogenetically distinct from $P$. syringae pv. lachrymans (Morris et al. 2000; Newberry et al. 2016).

Pseudomonas syringae strains isolated from cantaloupe in France were characterized as $P$. syringae pv. aptata based on biochemical and host range tests (Morris et al. 2000). In contrast, the P. syringae strains recovered from cantaloupe in China were metabolically and genetically distinct from $P$. syringae pv. aptata (Fig. 2, Table $3)$. Interestingly, the cantaloupe strain, NCPPB2916 recovered in Zimbabwe, was closely related to the $12 P$. syringae strains collected from cantaloupe in China, even though it was identified as
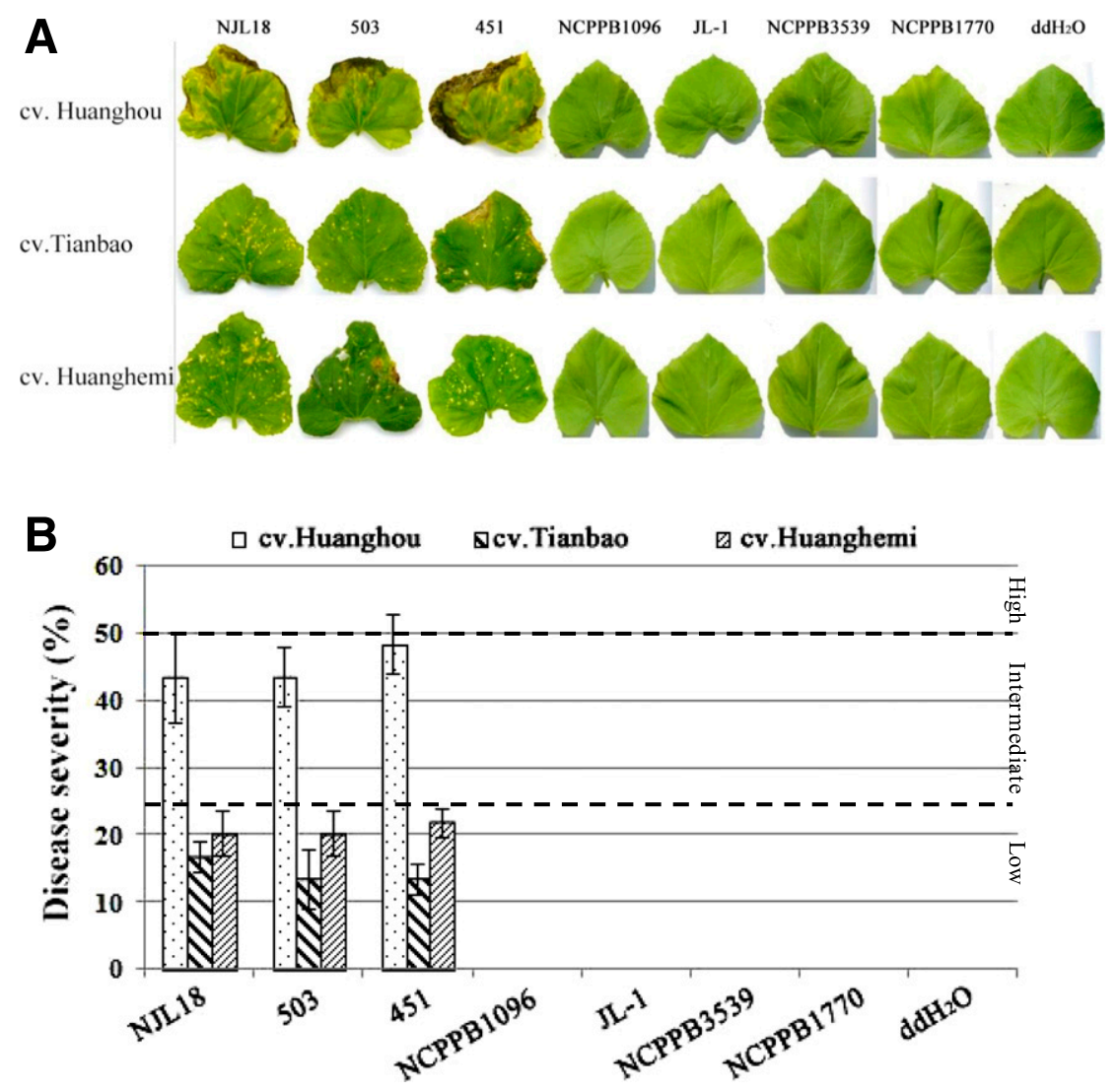

Fig. 4. Bacterial leaf blight symptoms (A) and severity (B) induced by representative strains of Pseudomonas syringae on melon leaves. Three $P$ seudomonas syringae strains isolated from cantaloupe (NJL18, 503, and 451) and two P. syringae pv. lachrymans strains isolated from cucumber (NCPPB1096 and JL-1) were spray-inoculated onto 3-week-old seedlings of three melon varieties (cv. Huanghou, Cucumis melo subsp. melo var. cantalupo, cv. Tianbao, Cucumis melo subsp. melo var. chinensis, and cv. Huanghemi, Cucumis melo subsp. melo var. cassaba) and evaluated at 14 days post inoculation (dpi). Disease severity is expressed as the proportion of leaflets area that was necrotic. Error bars represent standard errors of the means. 
$P$. syringae pv. lachrymans. This suggests that the $P$. syringae strains isolated from cantaloupe and cucumber may be heterogeneous worldwide. This heterogeneity was also reported for $P$. syringae strains isolated from watermelon, cantaloupe, and squash in the United States (Newberry et al. 2016). However, to draw a more definitive conclusion, more isolates from Africa and other regions must be analyzed.

The ability to cause disease on host plants and elicit a hypersensitive response on nonhost plants is a fundamental feature of most plant pathogenic bacteria that is controlled by $h r p$ genes (Bonas 1996). Li et al. (2002) reported that HrpA and HrpZ function as a conduit for the translocation of effector proteins. Inoue and Takikawa (2006) reported the $h r p Z$ and $h r p A$ gene sequences vary and are useful for characterizing $P$. syringae strains. Interestingly, $P$. syringae groupings based on these genes corresponded with the genomospecies system established by Gardan et al. (1999). In the current study, analysis of $h r p Z$ and $h r p A$ genes sequences facilitated the differentiation of $P$. syringae strains isolated from cantaloupe from the $P$. syringae pv. lachrymans strains isolated from cucumber (Fig. 3). This indicates that $P$. syringae pathovars that cause cucurbit diseases are not members of homogenous taxonomic unit (Newberry et al. 2016).

The pathovar classification of bacterial plant pathogens is an infrasubspecific level based on host range or capacity to cause disease on one or more plant hosts (Dye et al. 1980; Young et al. 1991). In this study, the virulence of $P$. syringae strains isolated from cantaloupe, cucumber, and beet was assessed on seedlings of three melon varieties. Although the host range of these strains was not comprehensively tested, strains that were isolated from hosts other than cantaloupe (NCPPB1096, JL-1, NCPPB3539, and NCPPB1770) were nonpathogenic on cantaloupe (Fig. 4). Recently, Newberry et al. (2016) suggested that pathogenicity assays may be of limited utility for pathovar classification of $P$. syringae strains recovered from cucurbits in the United States. However, since our population did not include $P$. syringae strains from watermelon, squash, and pumpkin in China, we are unable to directly test this hypothesis.

Based on our analyses, $P$. syringae strains isolated from cantaloupe were distinguishable from those isolated from cucumber. While melon and watermelon originated in Africa (Dane and Liu 2006; Vaughan and Geissler 2009), cucumber originated in India (Renner et al. 2007). It is possible that the genetic and phenotypic diversity between $P$. syringae strains from different hosts may be related to the host plant's geographical origin. Pseudomonas syringae strains may have adapted to their corresponding hosts during long periods of coevolution that led to different pathogenicity patterns. It is hypothesized that host specialization that manifests at the $P$. syringae pathovar level occurred long ago (Bui Thi Ngoc et al. 2010). This hypothesis is supported by the observation that $P$. syringae pv. lachrymans-like strains isolated from cucumber and other cucurbits (watermelon, cantaloupe, and squash) in the United States were genetically diverse (Newberry et al. 2016). Interestingly, $P$. syringae strains 03-113A, 03-19A, and 03-A13 from cantaloupe in Florida were moderately virulent on cantaloupe and watermelon (Newberry et al. 2016). Normally, farmers grow melon and watermelon crops in close proximity and $P$. syringae associated with melon may be introduced into watermelon fields. This practice could explain why $P$. syringae strains from cantaloupe may also infect watermelon.

In summary, we demonstrated that $P$. syringae strains isolated from BLB-infected cantaloupe in China were different from $P$. syringae pv. lachrymans isolated from cucumber and $P$. syringae pv. aptata. Our results suggest that $P$. syringae strains isolated from cantaloupe in China may represent a new phylotype. More generally, the $P$. syringae strains that cause foliar lesions and blighting of cucurbit host species are heterogeneous and an extensive revision of this group may be warranted.
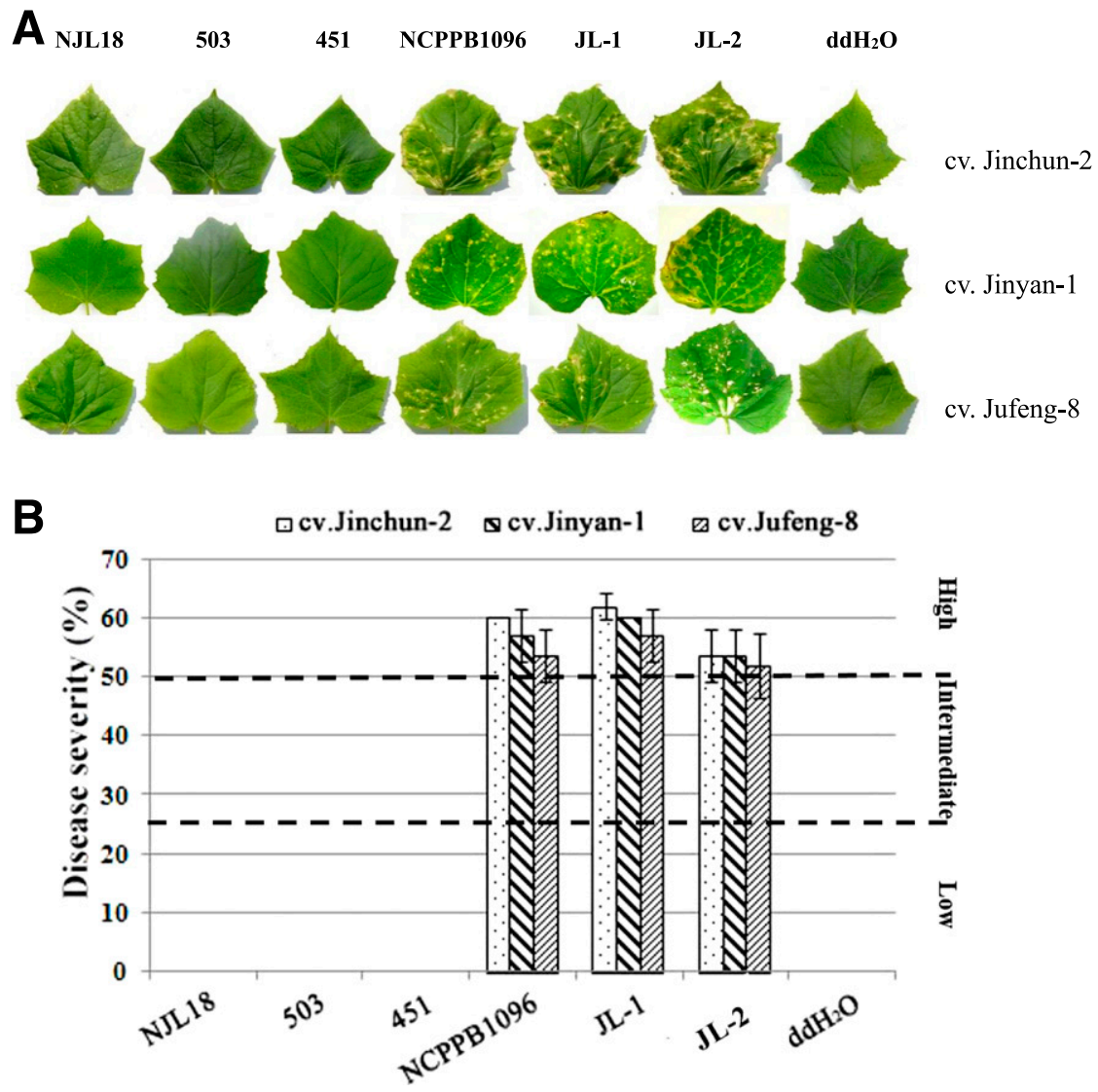

Fig. 5. Symptoms (A) and disease indices (B) caused by three Pseudomonas syringae strains isolated from cantaloupe (NJL18, 503 and 451 ) and three $P$. syringae pv. lachrymans strains isolated from cucumber (NCPPB1096, JL-1 and JL-2) on leaves of three cucumber varieties (cv. Jinchun-2, Jinyan-1 and Jufeng-8) at 14 days post inoculation (dpi). Disease severity is expressed as the proportion of leaflets area that was necrotic. Error bars represent standard errors of the means. 


\section{Acknowledgment}

This study was supported by the National Natural Science Funds of China (Grant No. 31500107), China Postdoctoral Science Foundation Funded Project (Project No. 2015M570461), and 12th Five Year Key Program for Science and Technology Development of China (Project No. 2012BAK11B02).

\section{Literature Cited}

Ait Tayeb, L., Ageron, E., Grimont, F., and Grimont, P. A. D. 2005. Molecular phylogeny of the genus Pseudomonas based on $r p o B$ sequences and application for the identification of isolates. Res. Microbiol. 156:763-773.

Andreani, N. A., Martino, M. E., Fasolato, L., Carraro, L., Montemurro, F., Mioni, R., Bordin, P., and Cardazzo, B. 2014. Tracking the blue: A MLST approach to characterise the Pseudomonas fluorescens group. Food Microbiol. 39:116-126.

Blancard, D., Lecoq, H., and Pitrat, M. 1991. Maladies des Cucurbita-cées: Observer, identifier, lutter. PHM Revue Horticle, Limoges and INRA, Paris.

Bonas, U. 1996. Hrp genes of phytopathogenic bacteria. Pages 79-98 in: Bacterial pathogenesis of plants and animals. J. L. Dangl, ed. Springer, Berlin.

Bradbury, J. F. 1986. Guide to Plant Pathogenic Bacteria, 1st Ed. Int. Mycolog. Inst., Kew, UK.

Bui Thi Ngoc, L., Vernière, C., Jouen, E., Ah-You, N., Lefeuvre, P., Chiroleu, F., Gagnevin, L., and Pruvost, O. 2010. Amplified fragment length polymorphism and multilocus sequence analysis-based genotypic relatedness among pathogenic variants of Xanthomonas citri pv. citri and Xanthomonas campestris pv. bilvae. Int. J. Syst. Evol. Microbiol. 60:515-525.

Bull, C. T., Clarke, C. R., Cai, R., Vinatzer, B. A., Jardini, T. M., and Koike, S. T. 2011. Multilocus sequence typing of Pseudomonas syringae sensual to confirms previously described genomospecies and permits rapid identification of $P$. syringae pv. coriandricola and $P$. syringae pv. apii causing bacterial leaf spot on parsley. Phytopathology 101:847-858.

Dane, F., and Liu, J. 2006. Diversity and origin of cultivated and citron type watermelon (Citrullus lanatus). Genet. Resour. Crop Evol. 54:1255-1265.

Dye, D. W., Bradbury, J. F., Goto, M., Hayward, A. C., Lelliott, R. A., and Schroth, M. N. 1980. International standards for naming pathovars of phytopathogenic bacteria and a list of pathovar names and pathotype strains. Rev. Plant Pathol. 59:153-158.

Gardan, L., Shafik, H., Belouin, S., Broch, R., Grimont, F., and Grimont, P. A. D. 1999. DNA relatedness among the pathovars of Pseudomonas syringae and description of Pseudomonas tremae sp. nov. and Pseudomonas cannabina sp. nov. (ex Sutic and Dowson 1959). Int. J. Syst. Bacteriol. 49:469-478.

Gutiérrez-Barranquero, J. A., de Vicente, A., Carrión, V. J., Sundin, G. W., and Cazorla, F. M. 2013. Recruitment and rearrangement of three different genetic determinants into a conjugative plasmid increase copper resistance in Pseudomonas syringae. Appl. Environ. Microbiol. 79:1028-1033.

Hwang, M. S. H., Morgan, R. L., Sarkar, S. F., Wang, P. W., and Guttman, D. S. 2005. Phylogenetic characterization of virulence and resistance phenotypes of Pseudomonas syringae. Appl. Environ. Microbiol. 71:5182-5191.

Inoue, Y., and Takikawa, Y. 2006. The $h r p Z$ and $h r p A$ genes are variable, and useful for grouping Pseudomonas syringae bacteria. J. Gen. Plant Pathol. 72:26-33.

James, M., Melcher, U., and Fletcher, J. 2014. Evaluating the impacts of stressors of Pseudomonas syringae pathovar tomato on the effectiveness of multi-locus variable number tandem repeat analysis and multi-locus sequence typing in microbial forensic investigations. Investig. Genet. 5:10.

Li, C. M., Brown, I., Mansfield, J. W., Stevens, C., Boureau, T., Romantschuk, M., and Taira, S. 2002. The Hrp pilus of Pseudomonas syringae elongates from its tip and acts as a conduit for translocation of the effector protein HrpZ. EMBO J. 21:1909-1915.

Morris, C. E., Glaux, C., Latour, X., Gardan, L., Samson, R., and Pitrat, M. 2000. The relationship of host range, physiology, and genotype to virulence on cantaloupe in Pseudomonas syringae from cantaloupe blight epidemics in France. Phytopathology 90:636-646.

Newberry, E. A., Jardini, T. M., Rubio, I., Roberts, P. D., Babu, B., Koike, S. T., Bouzar, H., Goss, E. M., Jones, J. B., Bull, C. T., and Paret, M. L. 2016. Angular leaf spot of cucurbit is associated with genetically diverse Pseudomonas syringae strains. Plant Dis. 100:1397-1404.

Parkinson, N., Bryant, R., Bew, J., and Elphinstone, J. 2010. Rapid phylogenetic identification of members of the Pseudomonas syringae species complex using the rpoD locus. Plant Pathol. 60:338-344.

Renner, S. S., Schaefer, H., and Kocyan, A. 2007. Phylogenetics of Cucumis (Cucurbitaceae): Cucumber (C. sativus) belongs in an Asian/Australian clade far from melon (C. melo). BMC Evol. Biol. 7:58.

Sarkar, S. F., Gordon, J. S., Martin, G. B., and Guttman, D. S. 2006. Comparative genomics of host-specific virulence in Pseudomonas syringae. Genetics 174: 1041-1056.

Sarkar, S. F., and Guttman, D. S. 2004. Evolution of the core genome of Pseudomonas syringae, a highly clonal, endemic plant pathogen. Appl. Environ. Microbiol. 70:1999-2012.

Schaad, N. W., Jones, J. B., and Chun, W. 2001. Page 7 in: Laboratory Guide for Identification of Plant Pathogenic Bacteria, 3rd Ed. American Phytopathological Society, St. Paul, MN.

Schaad, N. W., Postnikova, E., Sechler, A., Claflin, L. E., Vidaver, A. K., Jones, J. B., Agarkova, I., Ignatov, A., Dickstein, E., and Ramundo, B. A. 2008. Reclassification of subspecies of Acidovorax avenae as A. avenae (Manns 1905) emend, A. cattleyae (Pavarino, 1911) comb. nov., A. citrulli (Schaad et al., 1978) comb. nov., and proposal of A. oryzae sp. nov. Syst. Appl. Microbiol. 31:434-446.

Schaad, N. W., Sowell, G. J., Goth, R. W., Colwell, R. R., and Webb, R. E. 1978 Pseudomonas pseudoalcaligenes subsp. citrulli subsp. nov. Int. J. Syst. Bacteriol. 28:621

Smith, M. A. 1946. Bacterial spot of honeydew melon. Phytopathology 36: 943-949.

Sneath, P. H. A., and Sokal, R. P. 1973. Numerical taxonomy: The principles and practice of numerical classification. WH Freeman and Co., San Francisco.

Sun, F., and He, L. 1988. Angular leaf spot (ALS) of cucumber and its host range. Acta. Phytopathol. Sin. China 18:23-28.

Tamura, K., Peterson, D., Peterson, N., Stecher, G., Nei, M., and Kumar, S. 2011. MEGA 5: Molecular evolutionary genetics analysis using maximum likelihood, evolutionary distance, and maximum parsimony methods. Mol. Biol. Evol. 28:2731-2739.

Vaughan, J. G., and Geissler, C. A. 2009. Page 134 in: The New Oxford Book of Food Plants, 2nd Ed. Oxford Univ. Press, Oxford, UK.

Wang, P., Fan, J., Liu, C., Zhao, K., and Liang, C. 2012. The detection of Pseudomonas syringae pv. based on PCR. Chin. Agricul. Sci. Bull. 28:150-153.

Wang, Z., Chen, Q., Tian, Q., Li, Z., Zhu, S., and Zhao, W. 2011. Using PCR for rapid detection of Pseudomonas syringae pv. lachrymans. Plant Quar. China 25:29-32.

Wang, Z., Zhao, J., Mao, S., and Zhao, J. 2014. Study on the regional advantage layout of Chinese muskmelon industry. Chin. J. Agric. Resour. Reg. Plann. 35:128-133.

Wei, Y. 2009. Study on the angular leaf spot (ALS) of melon. Shanghai Veg. 2: 85-86.

Willems, A., Goor, M., Thielemans, S., Gilis, M., Kersters, K., and De Ley, J. 1992. Transfer of several phytopathogenic Pseudomonas species to Acidovorax as Acidovorax avenae subsp. avenae subsp. nov., comb. nov., Acidovorax avenae subsp. citruli, Acidovorax avenae subsp. cattleyae, and Acidovorax konjaci. Int. J. Syst. Bacteriol. 42:107-119.

Ye, C., and Ding, S. 2001. Several main diseases on Xinjiang muskmelon and their control. Plant Prot. China 27:34

Young, J. M. 1991. Pathogenicity and identification of the lilac pathogen, Pseudomonas syringae pv. syringae van Hall 1902. Ann. Appl. Biol. 118: 283-298.

Zeng, X., Qin, C., Han, Q., Liu, D., Liu, L., Zhang, W., and Hu, X. 2013. Occurrence and control of the angular leaf spot (ALS) of melon. J. Changjiang Vegetables. 17:56-57.

Zhang, X., Li, G., Ren, Y., and Wang, X. 2002. Identification of pathogen of bacterial disease of melon and pathogens'alternate predomination investigation in field in XinJiang. Sci. Agric. Sin. China 35:888-893. 